\title{
Accessibility of Enzymatically Delignified Bambusa bambos for Efficient Hydrolysis at Minimum Cellulase Loading: An Optimization Study
}

\author{
Arindam Kuila, ${ }^{1}$ Mainak Mukhopadhyay, ${ }^{1}$ D. K. Tuli, ${ }^{2}$ and Rintu Banerjee ${ }^{1}$ \\ ${ }^{1}$ Microbial Biotechnology and Downstream Processing Laboratory, Agricultural and Food Engineering Department, \\ Indian Institute of Technology, Kharagpur 721 302, India \\ ${ }^{2}$ R\&D Centre, Indian Oil Corporation Ltd., Faridabad 121 007, India
}

Correspondence should be addressed to Rintu Banerjee, rb@iitkgp.ac.in

Received 14 March 2011; Accepted 20 June 2011

Academic Editor: J. Guisan

Copyright (C) 2011 Arindam Kuila et al. This is an open access article distributed under the Creative Commons Attribution License, which permits unrestricted use, distribution, and reproduction in any medium, provided the original work is properly cited.

\begin{abstract}
In the present investigation, Bambusa bambos was used for optimization of enzymatic pretreatment and saccharification. Maximum enzymatic delignification achieved was $84 \%$, after $8 \mathrm{~h}$ of incubation time. Highest reducing sugar yield from enzymepretreated Bambusa bambos was $818.01 \mathrm{mg} / \mathrm{g}$ dry substrate after $8 \mathrm{~h}$ of incubation time at a low cellulase loading (endoglucanase, $\beta$-glucosidase, exoglucanase, and xylanase were $1.63 \mathrm{IU} / \mathrm{mL}, 1.28 \mathrm{IU} / \mathrm{mL}, 0.08 \mathrm{IU} / \mathrm{mL}$, and $47.93 \mathrm{IU} / \mathrm{mL}$, respectively). Enzymetreated substrate of Bambusa bambos was characterized by analytical techniques such as Fourier transformed infrared spectroscopy (FTIR), X-ray diffraction (XRD), and scanning electron microscopy (SEM). The FTIR spectrum showed that the absorption peaks of several functional groups were decreased after enzymatic pretreatment. XRD analysis indicated that cellulose crystallinity of enzyme-treated samples was increased due to the removal of amorphous lignin and hemicelluloses. SEM image showed that surface structure of Bambusa bambos was distorted after enzymatic pretreatment.
\end{abstract}

\section{Introduction}

Lignocellulosic biomass, for its large quantities and relatively low cost, is regarded as the potential renewable energy resource for cost-effective bioethanol production. Lignocellulosic bioethanol production involves three major steps, including pretreatment, enzymatic hydrolysis, and fermentation. Among all these steps, efficient hydrolysis of cellulose component of lignocellulosic biomass is the key step for costeffective bioethanol production. Cellulase is the key enzyme for hydrolysis of cellulose. Trichoderma reesei Rut C30 is one of the well-known cellulase (endoglucanase, $\beta$-glucosidase, exoglucanase, and xylanase) producing fungi. Since cellulase is still a relatively costly biocatalyst for commercially viable bioethanol production, this requires development of efficient hydrolysis of cellulose at low cellulase loading.

Lignin is key barrier which restricts the access of cellulase to cellulose. Laccase, a copper containing oxidase enzyme, can remove lignin effectively and increase the accessibility of cellulase to cellulose at mild operating conditions and minimal byproduct formation.

Bambusa bambos is a rapid growing lignocellulose available in abundance on the global scenario. The bamboos are woody tree-like grasses and have a long history as an exceptionally versatile and widely used resource. India is one of the leading countries in the world in bamboo production. (4.5 million tons) [1]. Bambusa bambos is one of the most important species of Bamboo, which grows in India. It has high cellulose (40-50\%) and moderate lignin (15-20\%) content [2]. If appropriate pretreatment and saccharification strategies are performed, Bambusa bambos can be used as potential feedstock for cost-effective bioethanol production. Structural characteristics and chemical compounds distribution of Bambusa bambos before and after pretreatment could be studied using FTIR, XRD, and SEM. This could reveal structural and chemical changes that occur when 
particular treatments are applied to produce an optimized and high-quality product development. In recent years some researchers made progress on the utilization of Bamboo, including pretreatments and saccharification [3-5], but there is no literature on the changes in physicochemical properties for enzyme-pretreated Bambusa bambos and saccharification at low cellulase loading.

In the present study, we investigated the possibility of enzymatic hydrolysis of laccase-pretreated Bambusa bambos at low cellulase loading. The objective of the study was to (1) optimize the laccase-mediated pretreatment of Bambusa bambos and evaluate the enzymatic pretreatment effect for efficient saccharification and (2) optimize the enzymatic hydrolysis of pretreated Bambusa bambos at low cellulase loading.

\section{Materials and Methods}

2.1. Lignocellulosic Substrate. Bambusa bambos (cellulose $47.49 \%$, hemicellulose $17.49 \%$, lignin $23.56 \%$, moisture $10.23 \%$, and ash $2.30 \%$ ) was collected from local forest of IIT Kharagpur, India. It was air dried overnight at $60^{\circ} \mathrm{C}$. Then it was milled to approximately $0.2 \mathrm{~mm}$ particle size and subsequently used for further studies.

2.2. Enzymes. Laccase and cellulase were produced from Pleurotus sp. and Trichoderma reesei Rut C30, respectively [6, 7]. Laccase and cellulase were centrifugedat 5,000 rpm for 5 minutes. The clear filtrate of laccase was used as crude laccase whose activity was determined spectrophotometrically [6]. One international unit $/ \mathrm{mL}(\mathrm{IU} / \mathrm{mL})$ of laccase activity was defined as the amount of enzyme capable of oxidizing $1 \mu \mathrm{mol}$ of ABTS per minute under the assay conditions. Clear supernatant of cellulase ( $\mathrm{pH} 5$ ) was used as crude cellulase whose activity was determined by following assay protocols $[8$, 9]. One international unit $/ \mathrm{mL}(\mathrm{IU} / \mathrm{mL})$ of cellulase activity was defined as the amount of enzyme required to produce $1 \mu \mathrm{mol}$ of glucose per minute under the assay conditions. The activity of endoglucanase, $\beta$-glucosidase, exoglucanase, and xylanase were $16.34 \mathrm{IU} / \mathrm{mL}, 12.80 \mathrm{IU} / \mathrm{mL}, 0.78 \mathrm{IU} / \mathrm{mL}$, and $479.33 \mathrm{IU} / \mathrm{mL}$, respectively.

\subsection{Enzymatic Pretreatment and Saccharification of Bambusa} bambos. Enzymatic pretreatment of Bambusa bambos was performed in Erlenmeyer flask, containing $10 \mathrm{~g}$ of substrate, $0.1 \mathrm{~mol} / \mathrm{L}$ of phosphate buffer ( $\mathrm{pH} 6.5$ to 7.5 ) and required volume of laccase. Samples were withdrawn periodically, and the solid residue was used for lignin estimation. After delignification the solid residue was washed with distilled water. Then it was air dried overnight at $60^{\circ} \mathrm{C}$ and subsequently used for further studies.

For enzymatic hydrolysis, pretreated sample of Bambusa bambos was taken in Erlenmeyer flask containing $18 \mathrm{~mL}$ of $0.1 \mathrm{~mol} / \mathrm{L}$ of phosphate buffer ( $\mathrm{pH} 4$ to 8 ) and $2 \mathrm{~mL}$ of cellulase enzyme. Sample aliquots were taken periodically and centrifuged at 2,000 rpm for 5 minutes. The supernatant was analyzed for reducing sugar by following dinitrosalicylic acid method [10]. The extent of hydrolysis was calculated as follows:

$$
\begin{aligned}
& \text { Saccharification }(\%) \\
& =100 \times[\text { Reducing sugar concentration obtained/ } \\
& \text { Potential sugar concentration } \\
& \text { in the pretreated substrate }] .
\end{aligned}
$$

2.4. Response Surface Methodology. Response Surface Methodology- (RSM-) based three level Central Composite Design (CCD) was employed for optimization of enzymatic pretreatment and saccharification of Bambusa bambos. For pretreatment of Bambusa bambos, five parameters were selected in the range $\mathrm{pH}(6.5-7.5)$, temperature $\left(35-45^{\circ} \mathrm{C}\right)$, liquid: solid ratio $(2-6 \mathrm{~mL} / \mathrm{g})$, incubation time $(4-8 \mathrm{~h})$, and enzyme concentration (400-600 IU/gds). For saccharification of pretreated Bambusa bambos, four parameters were selected in the range of $\mathrm{pH}(4-8)$, substrate concentration $(16-20 \mathrm{~mL} / \mathrm{g})$, temperature $\left(40-60^{\circ} \mathrm{C}\right)$, and incubation time (4-8 h). All the pretreatment and saccharification experiments were carried out in triplicates. In coded terms the lowest, central, and the highest level of the variables were -1 , 0 , and +1 , respectively. Tables 1 and 2 show the pretreatment and saccharification result, respectively.

\subsection{Analytical Methods}

2.5.1. FTIR, XRD, and SEM Study of Bambusa bambos. Fourier transformed infrared spectroscopy (FTIR) was performed in both the original and pretreated samples using the $\mathrm{KBr}$ pellet technique. Sample spectra were obtained over the range of $400 \mathrm{~cm}^{-1}$ and $4000 \mathrm{~cm}^{-1}$ with a spectral resolution of $0.5 \mathrm{~cm}^{-1}$.

The crystallinity of original and pretreated sample were determined by XRD1710 equipment using $\mathrm{CoK}_{\alpha}$ radiation $(\alpha=1.79 \AA)$ at $40 \mathrm{kV}$ and $20 \mathrm{~mA}$. All samples were scanned from $2 \theta=15$ to $75^{\circ}$ with scanning speed of $3^{\circ} / \mathrm{min}$. Crystallinity $(\%)$ was defined as $\left[\left(I_{002}-I_{\mathrm{am}}\right) / I_{002}\right] \times 100$, where $I_{002}$ represent maximum crystalline intensity peak at $2 \theta$ between $22^{\circ}$ and $23^{\circ}$ for cellulose $I$, and $I_{\mathrm{am}}$ representss minimum crystalline intensity peak at $2 \theta$ between $18^{\circ}$ and $19^{\circ}$ for cellulose $I$ [11].

To analyze surface characteristics of original and pretreated samples, Scanning electron microscopic (SEM) image was taken for both original and pretreated sample of Bambusa bambos. For SEM, dried sample was coated with gold and observed under JEOL JSM 5800 (Jeol Ltd., Tokyo, Japan) SEM.

\section{Result and Discussion}

3.1. Optimization of Enzymatic Pretreatment and Saccharifcation of Bambusa bambos. Using the designed experimental data (Table 1), the second-order polynomial model for 
TABle 1: Experimental design (conditions and responses) for enzymatic pretreatment of Bambusa bambos in terms of coded factor.

\begin{tabular}{|c|c|c|c|c|c|c|c|}
\hline \multirow{2}{*}{ Run order } & \multirow{2}{*}{$A_{1}$} & \multirow{2}{*}{$A_{2}$} & \multirow{2}{*}{$A_{3}$} & \multirow{2}{*}{$A_{4}$} & \multirow{2}{*}{$A_{5}$} & \multicolumn{2}{|c|}{ Delignification (\%) } \\
\hline & & & & & & Experimental & Predicted \\
\hline (1) & $\begin{array}{c}-1 \\
(6.5)\end{array}$ & $-1(35)$ & $-1(2)$ & $-1(400)$ & $+1(8)$ & 75.33 & 73.807 \\
\hline (2) & $+1(7.5)$ & $-1(35)$ & $-1(2)$ & $-1(400)$ & $-1(6)$ & 62.41 & 63.282 \\
\hline (3) & $\begin{array}{c}-1 \\
(6.5)\end{array}$ & $+1(45)$ & $-1(2)$ & $-1(400)$ & $-1(4)$ & 43.36 & 41.834 \\
\hline (4) & $+1(7.5)$ & $+1(45)$ & $-1(2)$ & $-1(400)$ & $+1(8)$ & 45.13 & 44.381 \\
\hline (5) & $-1(6.5)$ & $-1(35)$ & $+1(6)$ & $-1(400)$ & $-1(4)$ & 82.64 & 82.938 \\
\hline (6) & $+1(7.5)$ & $-1(35)$ & $+1(6)$ & $-1(400)$ & $+1(8)$ & 38.7 & 39.775 \\
\hline (7) & $-1(6.5)$ & $+1(45)$ & $+1(6)$ & $-1(400)$ & $+1(8)$ & 41.73 & 40.843 \\
\hline (8) & $+1(7.5)$ & $+1(45)$ & $+1(6)$ & $+1(600)$ & $-1(4)$ & 51.78 & 52.852 \\
\hline (9) & $+1(7.5)$ & $-1(35)$ & $-1(2)$ & $+1(600)$ & $+1(8)$ & 63.29 & 64.066 \\
\hline (10) & $\begin{array}{c}-1 \\
(6.5)\end{array}$ & $+1(45)$ & $-1(2)$ & $+1(600)$ & $+1(8)$ & 55.53 & 54.345 \\
\hline (11) & $+1(7.5)$ & $+1(45)$ & $-1(2)$ & $+1(600)$ & $-1(4)$ & 50.69 & 50.392 \\
\hline (12) & $\begin{array}{c}-1 \\
(6.5)\end{array}$ & $-1(35)$ & $+1(6)$ & $+1(600)$ & $+1(8)$ & 35.6 & 36.239 \\
\hline (13) & $+1(7.5)$ & $-1(35)$ & $+1(6)$ & $+1(600)$ & $-1(4)$ & 83.1 & 84.626 \\
\hline (14) & $\begin{array}{c}-1 \\
(6.5)\end{array}$ & +1 (45) & $+1(6)$ & $+1(600)$ & $-1(4)$ & 80.19 & 79.318 \\
\hline (15) & $+1(7.5)$ & $+1(45)$ & $+1(6)$ & $+1(600)$ & $+1(8)$ & 62.34 & 62.68 \\
\hline (16) & $\begin{array}{c}-1 \\
(6.5)\end{array}$ & $0(40)$ & $0(4)$ & $0(500)$ & $0(6)$ & 68.2 & 73.255 \\
\hline (17) & $+1(7.5)$ & $0(40)$ & $0(4)$ & $0(500)$ & $0(6)$ & 71.09 & 66.477 \\
\hline (18) & $0(7)$ & $-1(35)$ & $0(4)$ & $0(500)$ & $0(6)$ & 82.37 & 78.707 \\
\hline (19) & $0(7)$ & $+1(45)$ & $0(4)$ & $0(500)$ & $0(6)$ & 73.41 & 77.515 \\
\hline (20) & $0(7)$ & $0(40)$ & $-1(2)$ & $0(500)$ & $0(6)$ & 63.11 & 66.744 \\
\hline (21) & $0(7)$ & $0(40)$ & $+1(6)$ & $0(500)$ & $0(6)$ & 81.9 & 78.709 \\
\hline$(22)$ & $0(7)$ & $0(40)$ & $0(4)$ & $-1(400)$ & $0(6)$ & 63.4 & 65.84 \\
\hline (23) & $0(7)$ & $0(40)$ & $0(4)$ & $+1(600)$ & $0(6)$ & 80.2 & 78.203 \\
\hline (24) & $0(7)$ & $0(40)$ & $0(4)$ & $0(500)$ & $-1(4)$ & 45.12 & 44.92 \\
\hline (25) & $0(7)$ & $0(40)$ & $0(4)$ & $0(500)$ & $+1(8)$ & 80.72 & 82.234 \\
\hline$(26)$ & $0(7)$ & $0(40)$ & $0(4)$ & $0(500)$ & $0(6)$ & 82.6 & 80.736 \\
\hline$(27)$ & $0(7)$ & $0(40)$ & $0(4)$ & $0(500)$ & $0(6)$ & 74.7 & 80.736 \\
\hline$(28)$ & $0(7)$ & $0(40)$ & $0(4)$ & $0(500)$ & $0(6)$ & 80.05 & 80.736 \\
\hline (29) & $0(7)$ & $0(40)$ & $0(4)$ & $0(500)$ & $0(6)$ & 81.9 & 80.736 \\
\hline$(30)$ & $0(7)$ & $0(40)$ & $0(4)$ & $0(500)$ & $0(6)$ & 83.44 & 80.736 \\
\hline (31) & $0(7)$ & $0(40)$ & $0(4)$ & $0(500)$ & $0(6)$ & 84.1 & 80.736 \\
\hline (32) & $0(7)$ & $0(40)$ & $0(4)$ & $0(500)$ & $0(6)$ & 81.0 & 80.736 \\
\hline
\end{tabular}

the percent delignification in terms of coded factors is shown as follows:

$$
\begin{aligned}
Y_{1}= & -2314.71+639.76 A_{1}+44.65 A_{2}+191.75 A_{3} \\
& -5.27 A_{4}+58.34 A_{5}-43.48 A_{1}^{2}-0.10 A_{2}^{2} \\
& -2.00 A_{3}^{2}-4.29 A_{5}^{2}-7.17 A_{1} A_{2}-17.10 A_{1} A_{3}
\end{aligned}
$$

$$
\begin{aligned}
& +0.59 A_{1} A_{4}+4.10 A_{1} A_{5}-2.10 A_{2} A_{3}+0.05 A_{2} A_{4} \\
& -0.09 A_{2} A_{5}+0.10 A_{3} A_{4}-3.28 A_{3} A_{5}-0.02 A_{4} A_{5},
\end{aligned}
$$

where $Y_{1}$ is the percent delignification and $A_{1}, A_{2}, A_{3}$, $A_{4}$, and $A_{5}$ represent $\mathrm{pH}$, temperature, liquid: solid ratio, enzyme concentration, and incubation time, respectively. 
TABle 2: Experimental design (conditions and responses) for enzymatic saccharification of pretreated Bambusa bambos in terms of coded factor.

\begin{tabular}{|c|c|c|c|c|c|c|}
\hline \multirow{2}{*}{ Run order } & \multirow{2}{*}{$B_{1}$} & \multirow{2}{*}{$B_{2}$} & \multirow{2}{*}{$B_{3}$} & \multirow{2}{*}{$B_{4}$} & \multicolumn{2}{|c|}{ Reducing sugar (mg/g of substrate) } \\
\hline & & & & & Experimental & Predicted \\
\hline (1) & $-1(4)$ & $-1(40)$ & $-1(16)$ & $+1(8)$ & 671.21 & 671.15 \\
\hline (2) & $+1(8)$ & $-1(40)$ & $-1(16)$ & $-1(6)$ & 691.45 & 698.26 \\
\hline (3) & $-1(4)$ & $+1(60)$ & $-1(16)$ & $-1(4)$ & 621.67 & 632.60 \\
\hline (4) & $+1(8)$ & $+1(60)$ & $-1(16)$ & $+1(8)$ & 639.10 & 656.21 \\
\hline (5) & $-1(4)$ & $-1(40)$ & $+1(20)$ & $-1(4)$ & 695.47 & 683.00 \\
\hline (6) & $+1(8)$ & $-1(40)$ & $+1(20)$ & $+1(8)$ & 697.92 & 691.63 \\
\hline (7) & $-1(4)$ & $+1(60)$ & $+1(20)$ & $+1(8)$ & 700.13 & 705.95 \\
\hline (8) & $+1(8)$ & $+1(60)$ & $+1(20)$ & $-1(4)$ & 701.25 & 705.95 \\
\hline (9) & $+1(8)$ & $-1(40)$ & $-1(16)$ & $+1(8)$ & 698.32 & 693.32 \\
\hline (10) & $-1(4)$ & $+1(60)$ & $-1(16)$ & $+1(8)$ & 702.23 & 692.28 \\
\hline (11) & $+1(8)$ & $+1(60)$ & $-1(16)$ & $-1(4)$ & 657.13 & 647.90 \\
\hline$(12)$ & $-1(4)$ & $-1(40)$ & $+1(20)$ & $+1(8)$ & 667.27 & 675.42 \\
\hline (13) & $+1(8)$ & $-1(40)$ & $+1(20)$ & $-1(4)$ & 741.71 & 750.58 \\
\hline (14) & $-1(4)$ & $+1(60)$ & $+1(20)$ & $-1(4)$ & 696.09 & 696.60 \\
\hline (15) & $+1(8)$ & $+1(60)$ & $+1(20)$ & $+1(8)$ & 660.43 & 659.35 \\
\hline (16) & $-1(4)$ & $0(50)$ & $0(18)$ & $0(6)$ & 734.01 & 735.68 \\
\hline (17) & $+1(8)$ & $0(50)$ & $0(18)$ & $0(6)$ & 767.35 & 751.44 \\
\hline (18) & $0(6)$ & $-1(40)$ & $0(18)$ & $0(6)$ & 798.66 & 798.65 \\
\hline (19) & $0(6)$ & $+1(60)$ & $0(18)$ & $0(6)$ & 801.12 & 786.90 \\
\hline (20) & $0(6)$ & $0(50)$ & $-1(16)$ & $0(6)$ & 758.24 & 747.63 \\
\hline (21) & $0(6)$ & $0(50)$ & $+1(20)$ & $0(6)$ & 782.41 & 778.79 \\
\hline (22) & $0(6)$ & $0(50)$ & $0(18)$ & $0(6)$ & 801.23 & 808.36 \\
\hline (23) & $0(6)$ & $0(50)$ & $0(18)$ & $0(6)$ & 797.39 & 808.36 \\
\hline (24) & $0(6)$ & $0(50)$ & $0(18)$ & $-1(4)$ & 808.56 & 805.25 \\
\hline (25) & $0(6)$ & $0(50)$ & $0(18)$ & $+1(8)$ & 809.72 & 805.61 \\
\hline (26) & $0(6)$ & $0(50)$ & $0(18)$ & $0(6)$ & 801.43 & 808.36 \\
\hline (27) & $0(6)$ & $0(50)$ & $0(18)$ & $0(6)$ & 795.12 & 808.36 \\
\hline (28) & $0(6)$ & $0(50)$ & $0(18)$ & $0(6)$ & 811.06 & 808.36 \\
\hline (29) & $0(6)$ & $0(50)$ & $0(18)$ & $0(6)$ & 810.06 & 808.36 \\
\hline (30) & $0(6)$ & $0(50)$ & $0(18)$ & $0(6)$ & 802.62 & 808.36 \\
\hline (31) & $0(6)$ & $0(50)$ & $0(18)$ & $0(6)$ & 817.31 & 808.36 \\
\hline (32) & $0(6)$ & $0(50)$ & $0(18)$ & $0(6)$ & 803.08 & 808.36 \\
\hline
\end{tabular}

Whereas, using the experimental data (Table 2) the second-order polynomial model for the reducing sugar production (mg/gram dry substrate) of pretreated Bambusa bambos, in terms of coded factors, is shown as follows which are also given in coded terms:

$$
\begin{aligned}
Y_{2}= & -4626.87+260.67 B_{1}+17.35 B_{2}+433.93 B_{3} \\
& +82.19 B_{4}-16.20 B_{1}^{2}-0.16 B_{2}^{2}-11.29 B_{3}^{2} \\
& -0.73 B_{4}^{2}-0.73 B_{1} B_{2}-0.37 B_{1} B_{3}-3.21 B_{1} B_{4} \\
& +0.06 B_{2} B_{3}+0.15 B_{2} B_{4}-3.43 B_{3} B_{4},
\end{aligned}
$$

where the variables $B_{1}, B_{2}, B_{3}$, and $B_{4}$ represent $\mathrm{pH}$, temperature, substrate concentration, and incubation time, respectively, and $Y_{2}$ represents reducing sugar yield (mg/ gram dry substrate) from pretreated substrate.

Based on the experimental response, for enzymatic pretreatment, runs 12 and 31 had the minimum and maximum delignification, respectively, whereas, for saccharification of enzyme pretreated substrate, runs 3 and 31 had the minimum and maximum reducing sugar production, respectively. The ANOVA results of second-order response surface models for enzymatic pretreatment and saccharification of Bambusa bambos have been given in Table 3. From ANOVA analysis of regression model, for enzymatic pretreatment of Bambusa bambos at 20 degree of freedom, F-value was 22.07 and $P$ value was $<0.001$. For saccharification of enzymepretreated substrate $F$ and $P$ values were 64.72 and $<0.001$, respectively, at 20 degree of freedom. For both enzymatic 
TABLE 3: ANOVA analysis of RSM model for enzymatic pretreatment of Bambusa bamboos and saccharification of pretreated Bambusa bambos.

\begin{tabular}{|c|c|c|c|c|c|c|}
\hline Source & $\mathrm{DF}^{\mathrm{a}}$ & Seq $S^{b}$ & Adj SS ${ }^{b}$ & Adj $\mathrm{MS}^{\mathrm{c}}$ & $F$ & $P$ \\
\hline \multicolumn{7}{|c|}{ Pretreatment of Bambusa bamboos } \\
\hline Regression & 20 & 7547.10 & 7547.10 & 502.796 & 22.07 & $<0.001$ \\
\hline Linear & 5 & 1115.70 & 1395.38 & 375.443 & 16.32 & $<0.001$ \\
\hline Square & 5 & 2592.68 & 3959.72 & 473.038 & 46.32 & $<0.001$ \\
\hline Interaction & 10 & 3838.72 & 3838.72 & 383.872 & 22.45 & $<0.001$ \\
\hline Residual error & 11 & 188.05 & 188.05 & 17.096 & & \\
\hline Lack-of-fit & 5 & 128.62 & 128.62 & 25.724 & 2.60 & 0.138 \\
\hline Pure error & 6 & 59.44 & 57.44 & 9.906 & & \\
\hline Total & 32 & 7735.16 & & & & \\
\hline \multicolumn{7}{|c|}{$R^{2}=97.57 \%, R^{2}=93.15 \%$} \\
\hline \multicolumn{7}{|c|}{ Saccharification of pretreated Bambusa bamboos } \\
\hline Regression & 14 & 116738 & 116737.6 & 8338.4 & 64.72 & $<0.001$ \\
\hline Linear & 4 & 6116 & 22570.9 & 5642.7 & 43.80 & $<0.001$ \\
\hline Square & 4 & 103427 & 98888.2 & 24722.0 & 191.90 & $<0.001$ \\
\hline Interaction & 6 & 7195 & 7194.6 & 1199.1 & 9.31 & $<0.001$ \\
\hline Residual error & 17 & 2190 & 2190.1 & 128.8 & & \\
\hline Lack-of-fit & 9 & 1788 & 1788.0 & 198.7 & 3.95 & 0.033 \\
\hline Pure error & 8 & 402 & 402.1 & 50.3 & & \\
\hline \multirow[t]{2}{*}{ Total } & 32 & 118928 & & & & \\
\hline & & \multicolumn{2}{|c|}{$R^{2}=98.16 \%, R^{2}=96.64 \%$} & & & \\
\hline
\end{tabular}

${ }^{\mathrm{a}}$ Degrees of freedom.

${ }^{\mathrm{b}}$ Sum of squares.

${ }^{\mathrm{c}}$ Mean squares.

pretreatment and saccharification of Bambusa bambos $F$ values were several times higher than the $P$ values. So, $F$ and $P$ values indicated that the quadratic regression models for enzymatic pretreatment and saccharification of Bambusa bambos were significant, and insignificant $F$ and $P$ values of lack of fit for models indicated that experimental data obtained were in good agreement with the model [12]. The goodness of fit of regression models was checked by the determination coefficient $\left(R^{2}\right)$. The coefficients of determination $\left(R^{2}\right)$ were calculated to be 0.9757 and 0.9816 for enzymatic pretreatment and saccharification, respectively. For a good statistical model, $R^{2}$ value should be close to 1.0 .

The 3D response surface plots are generally the graphical representation of the regression equation. Figures 1 (a) and 1 (b) represent the 3D response surface plot for the optimum conditions of enzymatic delignification of Bambusa bambos. Each figure represents effect of two variables on percent delignification. From the analysis of the response surface plots, the optimum conditions for enzymatic delignification were $\mathrm{pH} 6.87$, temperature $35.26^{\circ} \mathrm{C}$, liquid : solid ratio $6: 1$, incubation time $8 \mathrm{~h}$, and enzyme concentration $400 \mathrm{IU} / \mathrm{mL}$. Under the optimum conditions, the maximum predicted delignification was $83 \%$, which was close to the experimental response $(84 \%)$. Reducing sugar yield could be significantly increased by removing about $80 \%$ of lignin from lignocellulosic biomass [13].
Figures 2(a) and 2(b) present the 3D response surface plots for the optimization conditions of saccharification of enzyme-pretreated substrate. Figure 2(a) shows the effect of substrate concentration $(\mathrm{mL} / \mathrm{g})$ and $\mathrm{pH}$, and Figure $2(\mathrm{~b})$ shows the effect of substrate concentration $(\mathrm{mL} / \mathrm{g})$ and incubation time $(\mathrm{h})$ on saccharification. From response surface plot analysis, under optimum conditions ( $\mathrm{pH} 6$, temperature $50^{\circ} \mathrm{C}$, substrate concentration $18 \mathrm{~mL} / \mathrm{g}$, and incubation time of $8 \mathrm{~h}$ ) the experimental maximum reducing sugar yield was $818.01 \mathrm{mg} / \mathrm{g}$ dry substrate which was close to predicted response. At low cellulase loading (endoglucanase, $\beta$ glucosidase, exoglucanase, and xylanase were $1.63 \mathrm{IU} / \mathrm{mL}$, $1.28 \mathrm{IU} / \mathrm{mL}, 0.08 \mathrm{IU} / \mathrm{mL}$, and $47.93 \mathrm{IU} / \mathrm{mL}$, respectively) the enhancement of saccharification (reducing sugar yield) reported here is much greater than that cited in other literatures $[12,14]$. It was also reported that physical and chemical pretreatment generates several toxic compounds which decrease the rate of saccharification as well as reducing sugar yield [15].

Similar reducing sugar yield ( $818.01 \mathrm{mg} / \mathrm{g}$ dry substrate) was reported by other authors at high cellulase loading [16, 17]. Cost-effective biofuel production needs low cellulase loading and higher reducing sugar yield in short incubation time [18]. The saccharification efficiency (71.28\%) obtained was in agreement with earlier reports $[19,20]$.

There are so many reports on using commercial cellulase for saccharification of different lignocellulosic biomass and 


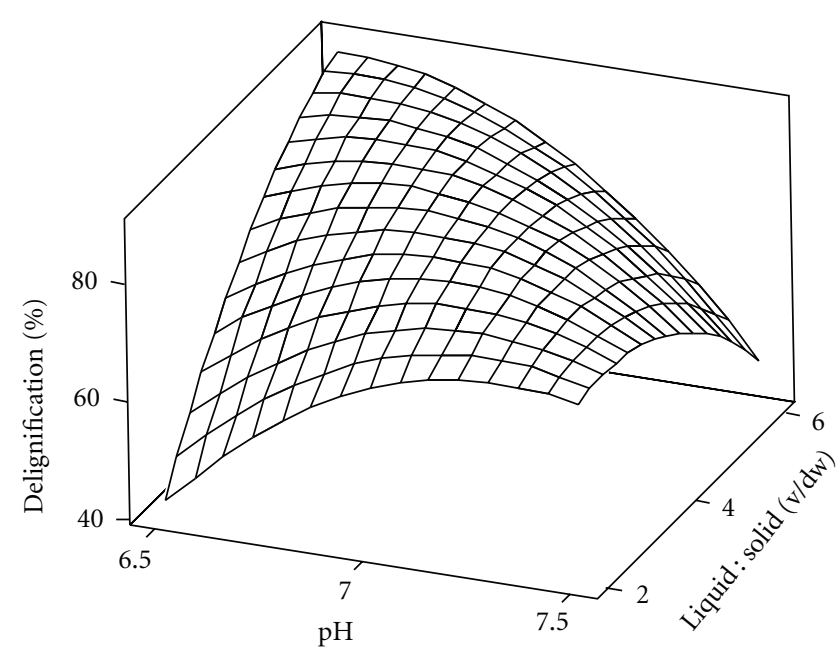

(a)

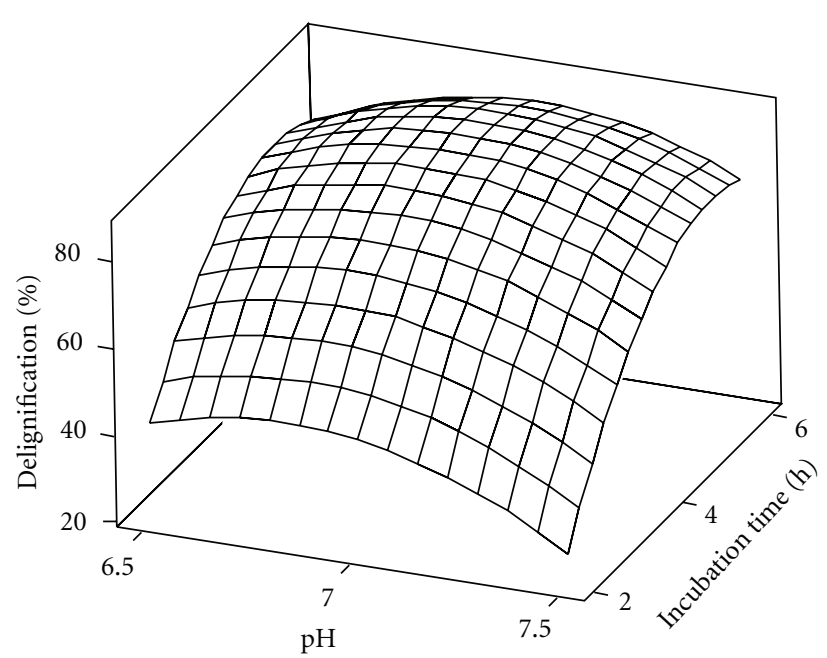

(b)

FIGURE 1: RSM plot showing (a) the effect of $\mathrm{pH}$ and liquid : solid ratio and (b) the effect of $\mathrm{pH}$ and incubation time on enzymatic pretreatment of Bambusa bambos.

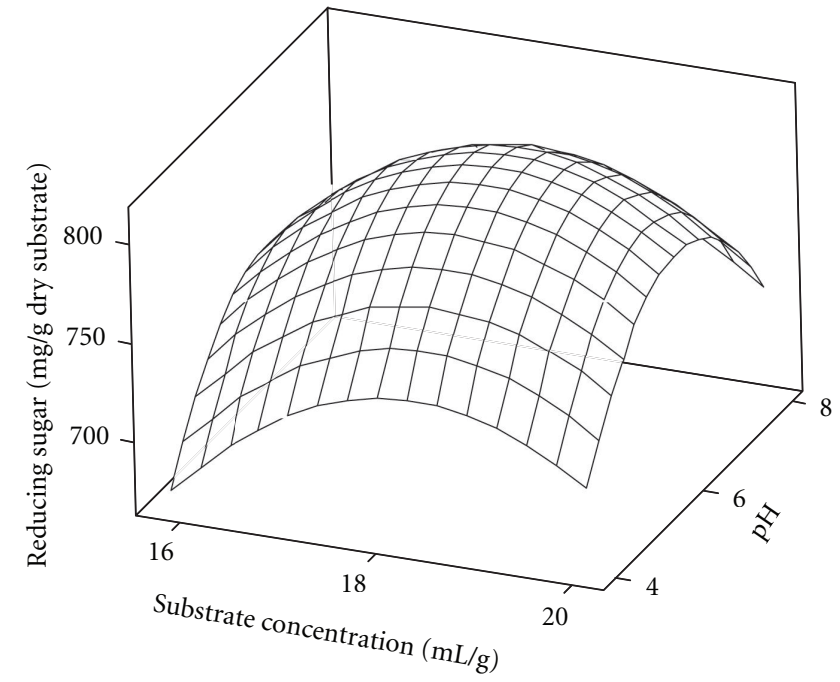

(a)

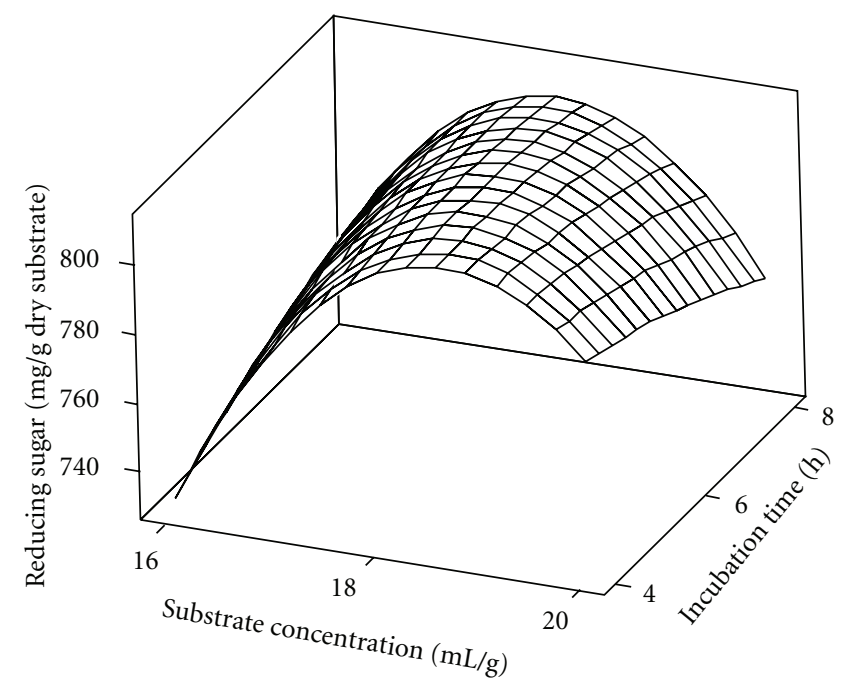

(b)

FIGURE 2: RSM plot showing (a) the effect of substrate concentration and $\mathrm{pH}$ and (b) substrate concentration and incubation time on saccharification of enzyme-pretreated Bambusa bambos.

also further addition of several additives was required [14, $21]$. In the present study, pretreatment was performed with crude laccase, and saccharification was performed with crude cellulase enzyme without addition of any additives.

3.2. Physical Properties of Pretreated Bambusa bambos. FTIR analysis was taken to qualitatively observe the changes of functional groups and further evaluate component modification. Significant changes in FTIR spectra could be seen after enzymatic pretreatment of Bambusa bambos (Figure 3). It shows that intensity at $3387 \mathrm{~cm}^{-1}$ (OH vibration), $2930 \mathrm{~cm}^{-1}$ (C-H methyl and methylene groups), $2379 \mathrm{~cm}^{-1}(\mathrm{C}=\mathrm{O}$ bonds in ketene groups), $1651 \mathrm{~cm}^{-1} \quad(\mathrm{C}=\mathrm{C}$ stretching),
$1515 \mathrm{~cm}^{-1}$ (C=C aromatic), $1249 \mathrm{~cm}^{-1}$ (O-H phenolic) and $1045 \mathrm{~cm}^{-1}$ (lignin) [22-25] were decreased after enzyme pretreatment. The reduced intensity indicates cleavage of lignin side chains [26]. These results highlight the effectiveness of enzymatic pretreatment for efficient saccharification of Bambusa bambos.

Lignocellulosic biomass is mainly composed of cellulose, hemicellulose, and lignin. Among several effecting factors, crystallinity is believed to significantly affect enzymatic saccharification of cellulose [27]. However, because of the impossibility of completely separating cellulose from other components of the fibers, the direct measurements of cellulose crystallinity in biomass were hindered [13]. 


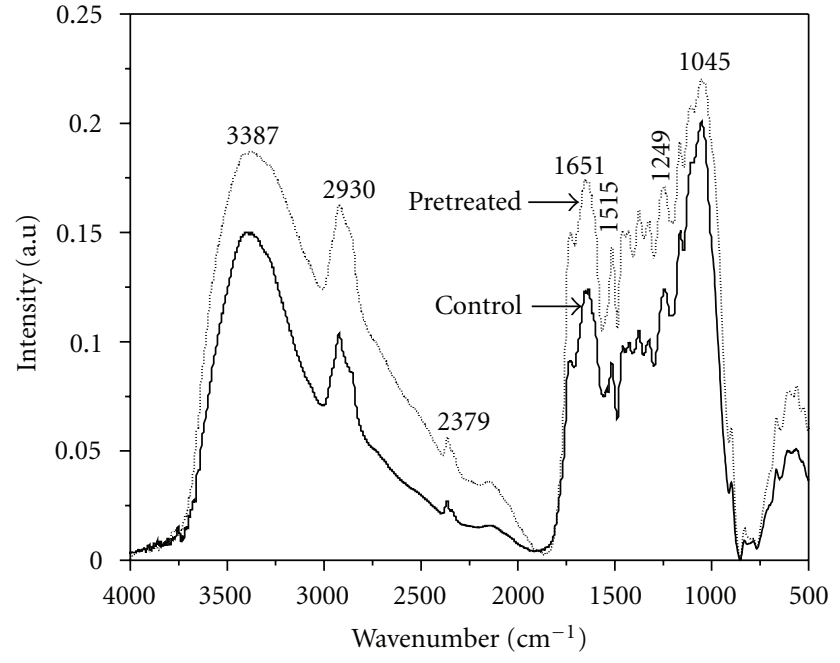

FIGURE 3: FTIR spectra of control and enzyme-pretreated Bambusa bambos.

The X-ray diffraction patterns of control and pretreated samples are presented in Figure 4. It was found that cellulose crystallinity of control and pretreated samples were $28.44 \%$ and $33 \%$, respectively. These results indicate effective pretreatment on Bambusa bambos which removes amorphous hemicellulose and lignin and expose all crystalline cellulose available and increase the rate of enzymatic saccharification [28].

SEM was used to determine changes in surface structure of Bambusa bambos after enzymatic pretreatment. SEM image of Bambusa bambos before and after enzymatic pretreatment is shown in Figure 5. It shows that surface structure in the control Bambusa bambos was rigid and highly ordered (Figure 5(a)), while the structure was distorted after pretreatment (Figure 5(b)). It was due to degradation of lignin after enzymatic pretreatment, which increased the surface area of cellulose, making it more accessible to cellulase [29].

\section{Conclusion}

Enzymatic pretreatment and saccharification of Bambusa bambos were carried out using laccase and cellulase enzyme, respectively. The conditions for enzymatic pretreatment and saccharification of Bambusa bambos were optimized by using RSM-based CCD. Using laccase optimum delignification (84\%) was achieved after $8 \mathrm{~h}$ of incubation time. Maximum reducing sugar yield ( $818.01 \mathrm{mg} /$ gram dry substrate) from enzyme-pretreated substrate was attained after $8 \mathrm{~h}$ of incubation time at low cellulase loading. FTIR, XRD, and SEM study further revealed the effectiveness of enzymatic pretreatment for efficient saccharification of Bambusa bambos.

\section{Acknowledgment}

The authors sincerely acknowledge Petrotech Society, New Delhi, for financial support.

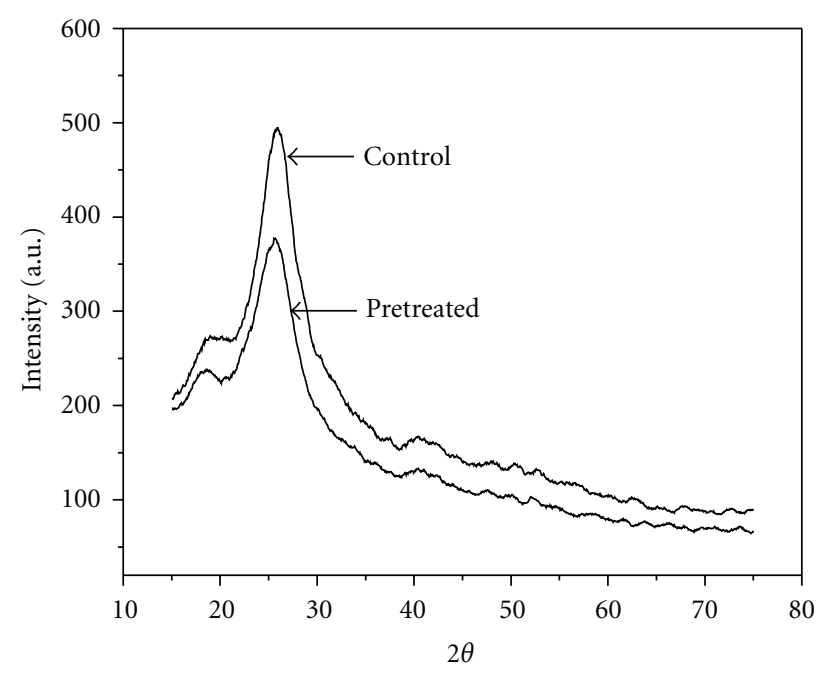

FIGURE 4: XRD diagram of control and enzyme-pretreated Bambusa bambos.

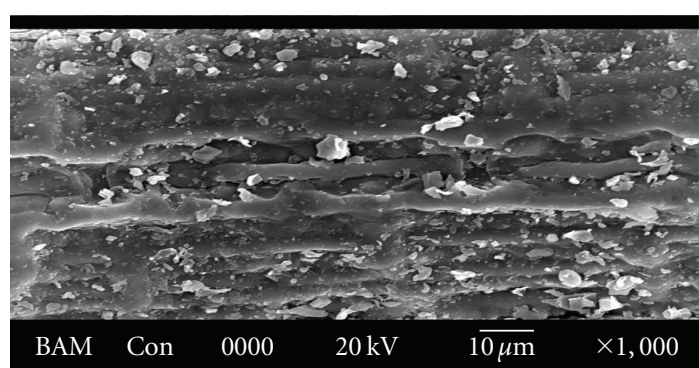

(a)

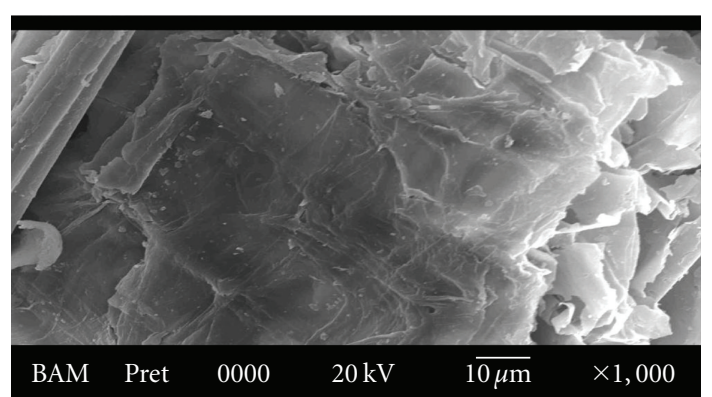

(b)

FIGURE 5: SEM view of (a) control and (b) enzyme-pretreated sample of Bambusa bambos.

\section{References}

[1] J. K. Rawat and D. C. Khanduri, "The status of Bamboo and Rattan in India," INBAR, 1999, http://www.inbar .int/documents/country\%20report/INDIA.htm.

[2] B. O. Ogunsile and C. F. Uwajeh, "Evaluation of the pulp and paper potentials of a Nigerian grown Bambusa vulgaris," World Applied Science Journal, vol. 6, no. 4, pp. 536-541, 2009.

[3] R. Lou, S. B. Wu, and G. J. Lv, "Effect of conditions on fast pyrolysis of bamboo lignin," Journal of Analytical and Applied Pyrolysis, vol. 89, no. 2, pp. 191-196, 2010. 
[4] N. Sathitsuksanoh, Z. Zhu, T. J. Ho, M. D. Bai, and Y. H. P. Zhang, "Bamboo saccharification through cellulose solventbased biomass pretreatment followed by enzymatic hydrolysis at ultra-low cellulase loadings," Bioresource Technology, vol. 101, no. 13, pp. 4926-4929, 2010.

[5] Y. Yamashita, M. Shono, C. Sasaki, and Y. Nakamura, "Alkaline peroxide pretreatment for efficient enzymatic saccharification of bamboo," Carbohydrate Polymers, vol. 79, no. 4, pp. 914920, 2010.

[6] S. S. Bhattacharya and R. Banerjee, "Laccase mediated biodegradation of 2,4-dichlorophenol using response surface methodology," Chemosphere, vol. 73, no. 1, pp. 81-85, 2008.

[7] M. Das, R. Banerjee, and S. Bal, "Multivariable parameter optimization for the endoglucanase production by Trichoderma reesei Rut C30 from Ocimum gratissimum seed," Brazilian Archives of Biology and Technology, vol. 51, no. 1, pp. 35-41, 2008.

[8] T. W. Jeffries, V. W. Yang, and M. W. Davis, "Comparative study of xylanase kinetics using dinitrosalicylic, arsenomolybdate, and ion chromatographic assays," Applied Biochemistry and Biotechnology A, vol. 70-72, pp. 257-265, 1998.

[9] Q. Zhang, C. M. Lo, and L. K. Ju, "Factors affecting foaming behavior in cellulase fermentation by Trichoderma reesei Rut C-30," Bioresource Technology, vol. 98, no. 4, pp. 753-760, 2007.

[10] G. L. Miller, "Use of dinitrosalicylic acid reagent for determination of reducing sugar," Analytical Chemistry, vol. 31, no. 3, pp. 426-428, 1959.

[11] L. Segal, J. J. Creely, A. E. Martin, and C. M. Conrad, "An empirical methods for estimating the degree of crystallinity of native cellulose using the X-ray diffraction," Textile Research Journal, vol. 29, no. 10, pp. 786-794, 1959.

[12] J. P. O’Dwyer, L. Zhu, C. B. Granda, and M. T. Holtzapple, "Enzymatic hydrolysis of lime-pretreated corn stover and investigation of the $\mathrm{HCH}-1$ Model: inhibition pattern, degree of inhibition, validity of simplified HCH-1 Model," Bioresource Technology, vol. 98, no. 16, pp. 2969-2977, 2007.

[13] X. B. Zhao, L. Wang, and D. H. Liu, "Peracetic acid pretreatment of sugarcane bagasse for enzymatic hydrolysis: a continued work," Journal of Chemical Technology and Biotechnology, vol. 83, no. 6, pp. 950-956, 2008.

[14] R. C. Kuhad, R. Gupta, Y. P. Khasa, and A. Singh, "Bioethanol production from Lantana camara (red sage): pretreatment, saccharification and fermentation," Bioresource Technology, vol. 101, no. 21, pp. 8348-8354, 2010.

[15] P. Alvira, E. Tomás-Pejó, M. Ballesteros, and M. J. Negro, "Pretreatment technologies for an efficient bioethanol production process based on enzymatic hydrolysis: a review," Bioresource Technology, vol. 101, no. 13, pp. 4851-4861, 2010.

[16] B. E. Dale, C. K. Leong, T. K. Pham, V. M. Esquivel, I. Rios, and V. M. Latimer, "Hydrolysis of lignocellulosics at low enzyme levels: application of the AFEX process," Bioresource Technology, vol. 56, no. 1, pp. 111-116, 1996.

[17] S. McIntosh and T. Vancov, "Enhanced enzyme saccharification of Sorghum bicolor straw using dilute alkali pretreatment," Bioresource Technology, vol. 101, no. 17, pp. 6718-6727, 2010.

[18] M. J. Taherzadeh and K. Karimi, "Enzyme based hydrolysis processes for ethanol from lignocellulosic materials: a review," BioResources, vol. 2, no. 4, pp. 707-738, 2007.

[19] M. G. Adsul, J. E. Ghule, H. Shaikh et al., "Enzymatic hydrolysis of delignified bagasse polysaccharides," Carbohydrate Polymers, vol. 62, no. 1, pp. 6-10, 2005.
[20] M. Jeya, Y. W. Zhang, I. W. Kim, and J. K. Lee, "Enhanced saccharification of alkali-treated rice straw by cellulase from Trametes hirsuta and statistical optimization of hydrolysis conditions by RSM," Bioresource Technology, vol. 100, no. 21, pp. 5155-5161, 2009.

[21] M. Zhang, P. Shukla, M. Ayyachamy, K. Permaul, and S. Singh, "Improved bioethanol production through simultaneous saccharification and fermentation of lignocellulosic agricultural wastes by Kluyveromyces marxianus 6556," World Journal of Microbiology and Biotechnology, vol. 26, no. 6, pp. 1041-1046, 2010.

[22] T. Dizhbite, N. Mironova-Ulmane, A. Volperts et al., "Elaboration and characterization of organic/inorganic hybrid nanoporous material incorporating Keggin-type Mo-Si polyanions," Journal of Physics, vol. 93, no. 1, Article ID 012011, 7 pages, 2007.

[23] N. N. Chopabaeva, E. E. Ergozhin, A. T. Tasmagambet, Y. S. Kramorenko, I. S. Stepanova, and M. M. Aznabakieva, "Detoxification of biological fluids by lignocellulose ionexchangers," Chemistry of Natural Compounds, vol. 44, no. 4, pp. 497-502, 2008.

[24] R. Bodirlau and C. A. Teaca, "Fourier transform infrared spectroscopy and thermal analysis of lignocellulose filters treated with organic anhydrides," Romanian Journal of Physics, vol. 54, no. 1-2, pp. 93-104, 2008.

[25] J. de Celis, N. E. Amadeo, and A. L. Cukierman, "In situ modification of activated carbons developed from a native invasive wood on removal of trace toxic metals from wastewater," Journal of Hazardous Materials, vol. 161, no. 1, pp. 217-223, 2009.

[26] E. Windeisen, C. Strobel, and G. Wegener, "Chemical changes during the production of thermo-treated beech wood," Wood Science and Technology, vol. 41, no. 6, pp. 523-536, 2007.

[27] S. D. Mansfield, C. Mooney, and J. N. Saddler, "Substrate and enzyme characteristics that limit cellulose hydrolysis," Biotechnology Progress, vol. 15, no. 5, pp. 804-816, 1999.

[28] J. Gabhane, S. P. M. Prince William, A. N. Vaidya, K. Mahapatra, and T. Chakrabarti, "Influence of heating source on the efficacy of lignocellulosic pretreatment-a cellulosic ethanol perspective," Biomass and Bioenergy, vol. 35, no. 1, pp. 96-102, 2011.

[29] M. F. Li, Y. M. Fan, F. Xu, R. C. Sun, and X. L. Zhang, "Cold sodium hydroxide/urea based pretreatment of bamboo for bioethanol production: characterization of the cellulose rich fraction," Industrial Crops and Products, vol. 32, no. 3, pp. 551559, 2010. 

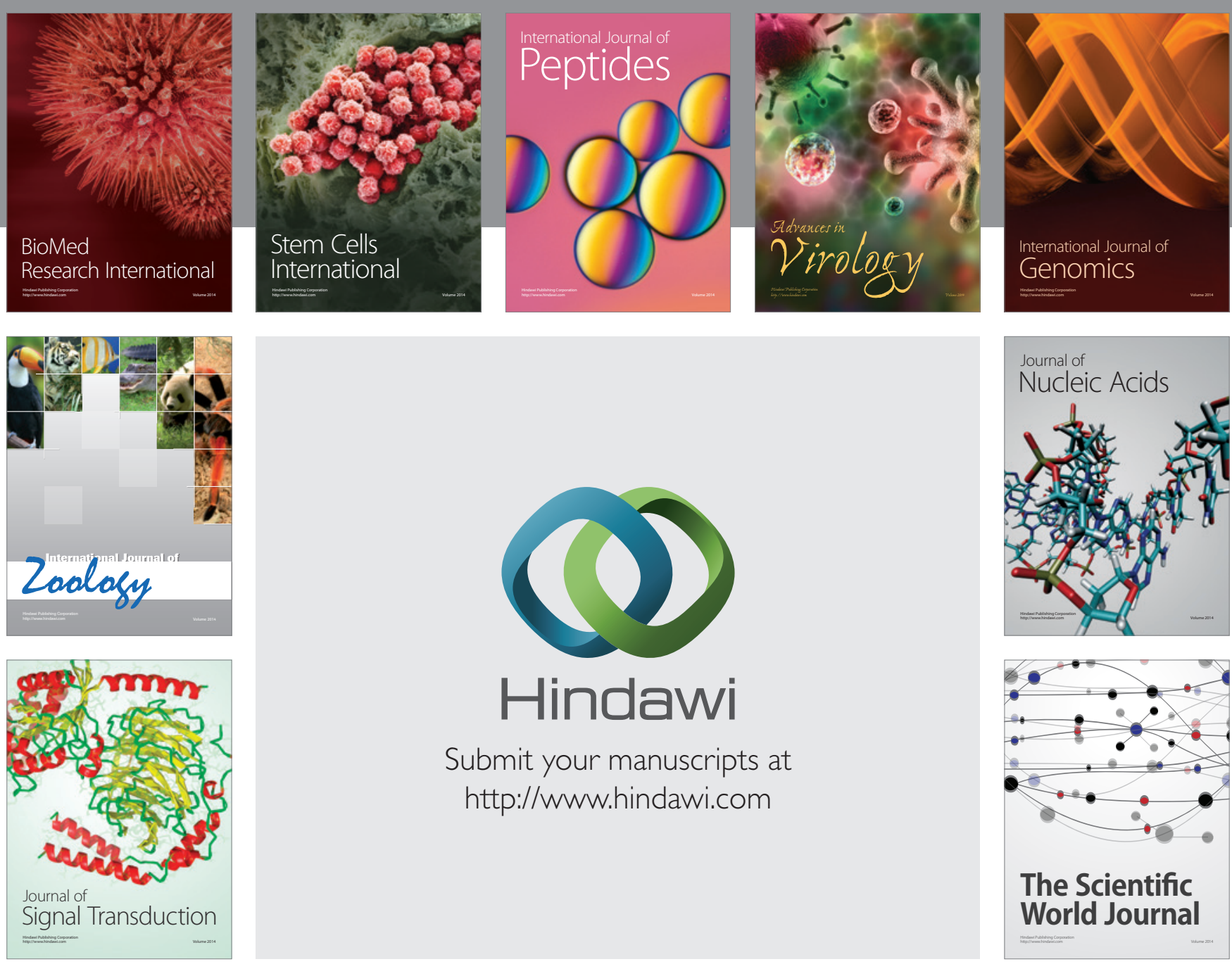

Submit your manuscripts at

http://www.hindawi.com
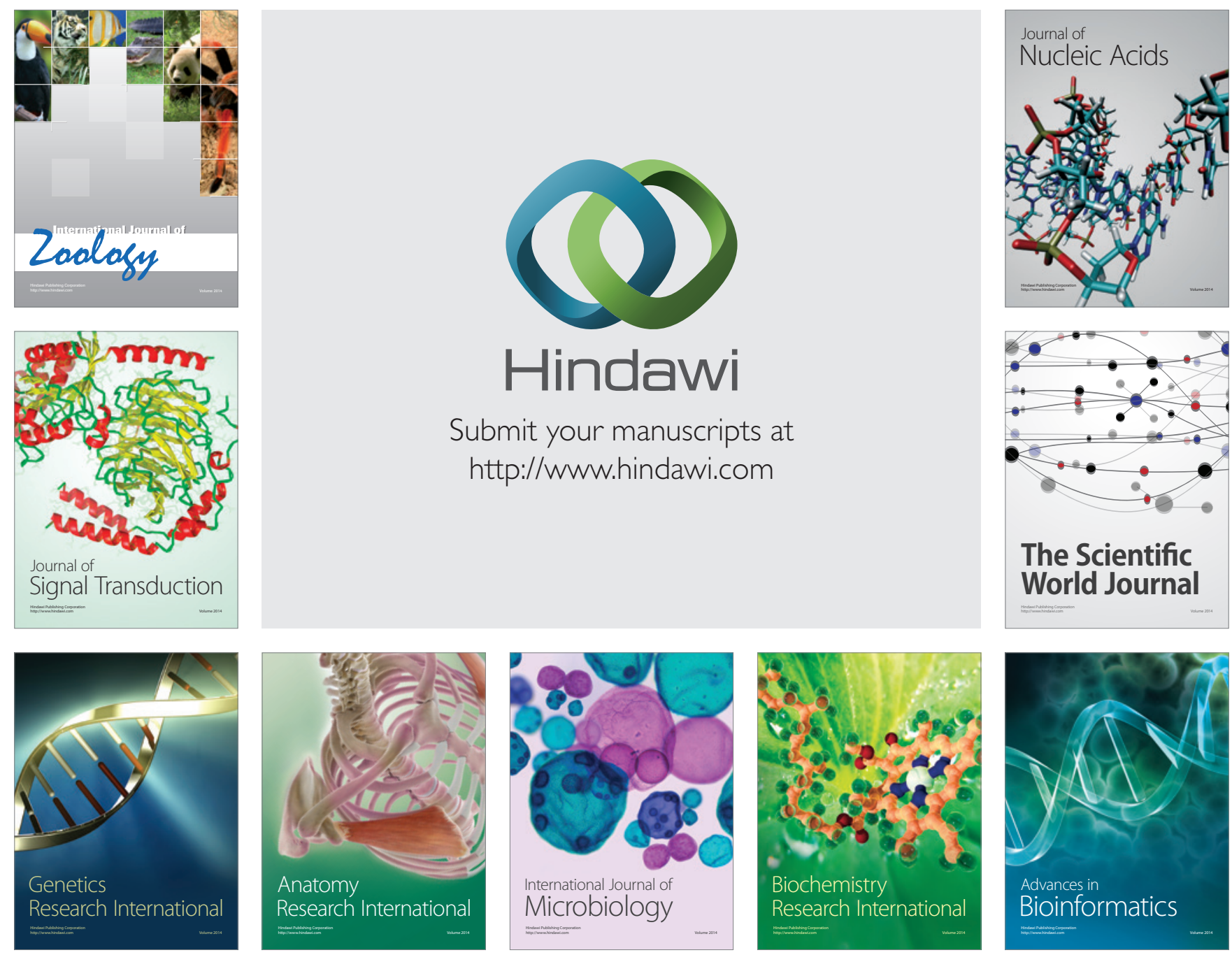

The Scientific World Journal
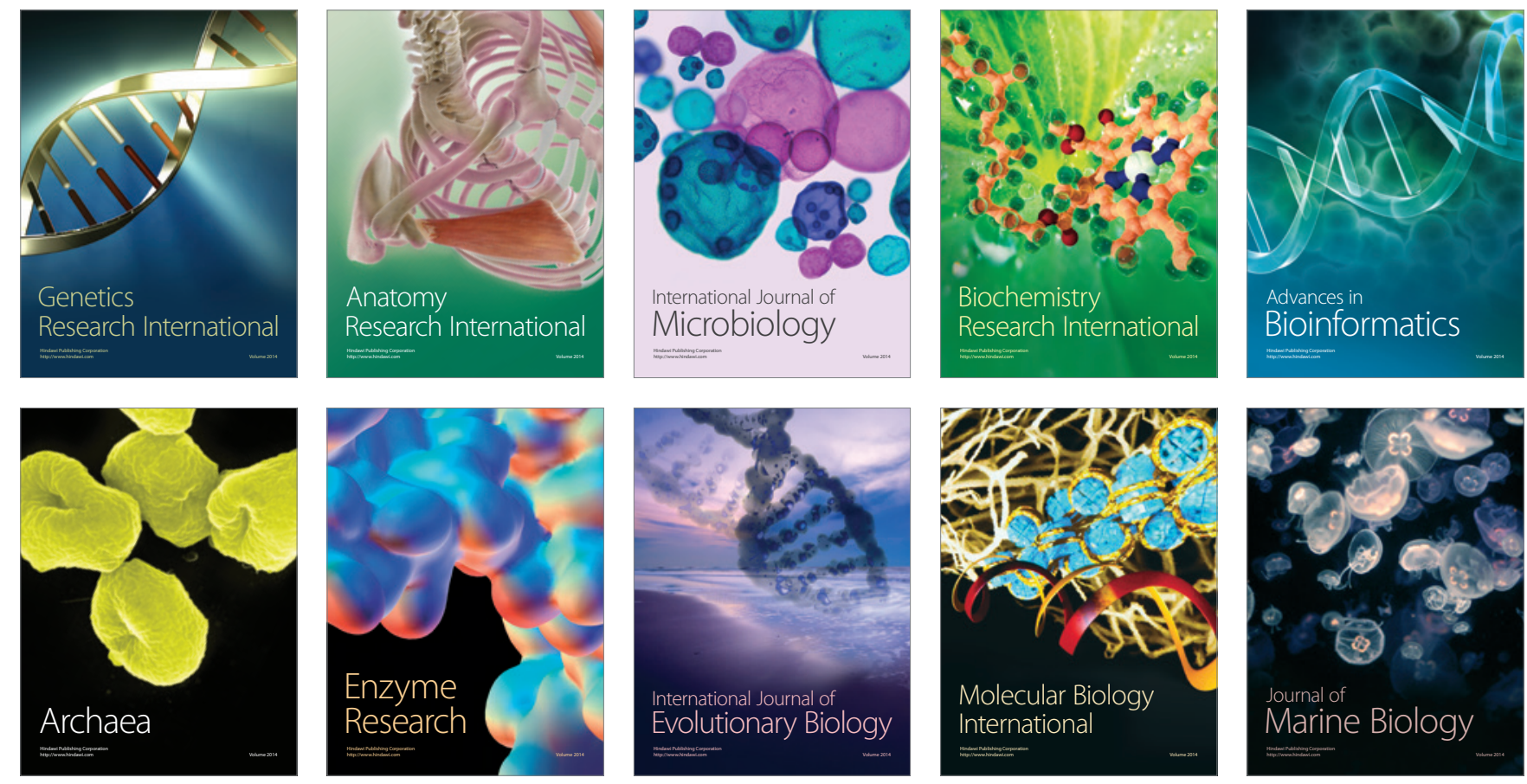